\title{
Interação, afeto e construção de sentidos entre crianças na brinquedoteca
}

Ivone Martins de Oliveira

Ademir Gebara

Universidade Federal do Espírito Santo

\section{Resumo}

Contextos em que as crianças interagem sem uma intervenção mais intensa dos adultos, como nos momentos de atividades livres em uma brinquedoteca, revelam-se significativos para problematizar e discutir aspectos referentes ao desenvolvimento infantil. De que maneira ocorrem as interações entre as crianças nesse espaço? Que pistas elas fornecem para uma compreensão dos fatores envolvidos no percurso de construção do "eu" entre essas crianças? Qual o papel do outro/criança nesse processo? Essas são algumas questões que o presente estudo busca discutir, tomando como base as contribuições de Vigotski sobre o desenvolvimento da consciência, as de Wallon relativas ao papel do outro na consciência do eu, e as de Elias, referentes à relação entre o sentido que o sujeito constrói sobre sua vida e os sentidos que os outros atribuem a ele. A análise dos dados relativos a observações de interações entre crianças e de crianças com adultos em uma brinquedoteca e, em especial, de duas crianças, um menino com síndrome de Down que vive com sua família e uma menina que mora em um orfanato, indica que, na relação estabelecida com o outro, mais do que um sentido único, o que se destaca é uma multiplicidade de sentidos a respeito do eu e do outro, acompanhada de ressonâncias afetivas que podem ser variadas e até contraditórias.

\section{Palavras-chave}

Interação - Afeto - Relação eu-outro - Brinquedoteca. 


\title{
Interaction, affection and the construction of meaning among children in a toy library
}

Ivone Martins de Oliveira

Ademir Gebara

Universidade Federal do Espírito Santo

\begin{abstract}
Contexts in which children interact without close interference from adults, as in times of free activities in a toy library, are revealed to be significant in problematizing and discussing aspects related to child development. How do the interactions occur among children in this space? What clues do they offer to the understanding of the factors involved in the construction of the "self" in these children? What is the role of the other/child in this process? These are some of the questions that the present study seeks to discuss, taking as its point of departure Vygotsky's contributions to the development of consciousness, those of Wallon on the role of the other in the awareness of the self, and those of Elias referring to the relation between the meaning the subject constructs about his life and the meanings attributed to it by others. The analysis of the data related to observations of the interactions between children and between children and adults in a toy library and, in particular between two children, a boy with Down Syndrome who lives with his family and a girl who lives in an orphanage, indicates that in the relationship established with the other what stands out is not so much a unique meaning, but a multiplicity of meanings of the self and the other, accompanied by affective resonances that can be varied and even contradictory.
\end{abstract}

Keywords

Interaction - Affection - Self-other relationship - Toy library.

Contact:

Ivone Martins de Oliveira

Av. Mário Corteletti, 210, apto 304

29.065.120-Vitória-ES

E-mail: ivone.mo@terra.com.br 
Este trabalho tem como objetivo discutir alguns aspectos da dimensão afetiva que perpassam a relação eu-outro e a constituição do sujeito. Para isso, inicialmente, retoma alguns postulados centrais da obra de Vigotski e de Wallon, bem como as convergências entre esses autores e Norbert Elias, visto que eles trazem contribuições inestimáveis para pensar a constituição social e histórica do sujeito, ao problematizarem o afetivo na relação eu-outro. Em seguida, para aprofundar a discussão, apresenta alguns achados de uma pesquisa empírica realizada com crianças em uma brinquedoteca.

Vigotski (1996; 2000) discute sobre o desenvolvimento das funções psicológicas superiores e da personalidade, apontando o papel fundamental do plano intersubjetivo na constituição do psiquismo humano. Recorre a Marx para afirmar: "A natureza psicológica da pessoa é o conjunto das relações sociais, transferidas para dentro e que se tornaram funções da personalidade e formas da sua estrutura" (Vigotski, 2000, p. 27). Para discutir a conversão de processos sociais em funções e componentes psíquicos, o autor destaca a função dos signos e coloca em relevo a significação.

Em sua obra, enfoca o papel mediador da palavra, apontando o significado e o sentido como primordiais no desenvolvimento da consciência. O signo é, ao mesmo tempo, lugar de constituição e expressão dos modos de vida culturalmente elaborados e elemento constituidor das formas superiores de pensamento. Em uma direção semelhante, Bakhtin (1986) afirma que a

[...] consciência adquire forma e existência nos signos criados por um grupo organizado, no curso de suas relações sociais. Os signos são alimento da consciência individual, a matéria de seu desenvolvimento, e ela reflete sua lógica e suas leis. (p. 35)

Retomando estudos realizados sobre a consciência do eu, Wallon (1975) destaca e problematiza as ideias de uma tendência que considera que a origem da consciência ocorre no âmbito individual e que seu percurso de desenvolvimento é marcado por uma progressiva "socialização" dessa entidade primária. Contrapondo-se a essa visão, o autor ressalta que não se trata de um "eu" que paulatinamente se abre ao mundo social, mas sim de um ser que progressivamente se individualiza. Isso porque esse "eu" toma forma a partir das - e nas - relações que estabelece com os outros. Segundo esse autor:

0 período inicial do psiquismo parece ter sido, contrariamente à concepção tradicional, um estado de indivisão entre o que releva da situação exterior ou do próprio sujeito. Tudo o que chega simultaneamente à sua consciência fica confundido nela ou pelo menos as delimitações que se podem fazer nela não são primeiro as do eu e dos outros, as do acto pessoal e do seu objecto exterior. A união da situação ou do ambiente e do sujeito começa por ser global e indiscernível. (p. 155)

Inicialmente o que há é uma indiferenciação em relação aos outros e ao meio ambiente. Em meio a essa forma de relação em que o "eu" se (con)funde com o outro, em que as fronteiras entre ambos estão ainda por se estabelecer, destaca a natureza e o papel funcional das emoções. Para Wallon (1975), a emoção "[...] corresponde a um estado psíquico mais primitivo que a tomada de consciência pela qual a pessoa afirma a sua autonomia [...]" (p. 154) e, por sua função comunicativa e seu poder de contágio, contribui para o estabelecimento das condições interativas necessárias não somente à sobrevivência da espécie, mas também à própria constituição do "eu".

No processo de individualização, de distinção do "eu", exercem função de relevo os exercícios e os jogos de alternância, nos quais a criança, paulatinamente, vai ocupando diferentes papéis: pode colocar-se no lugar de quem atua ou de quem sofre a ação. Nesse momento, embora haja uma diferenciação en- 
tre o eu e o outro, há ainda uma espécie de equivalência entre eles. Um passo decisivo para a estabilização do eu em relação ao outro é dado a partir das situações de oposição vivenciadas pela criança em diferentes planos: o eu se afirma ao mesmo tempo em que se opõe ao outro, em circunstâncias diferenciadas.

A obra desses autores evidencia, de modo radical, a participação da cultura e da história em nossa constituição como seres humanos, participação que acontece por meio da figura do outro. Nessa constituição, tanto Vigotski como Wallon atribuem ao afetivo um papel fundamental. Wallon, mais que Vigotski, dedica-se à discussão sobre a afetividade e o papel da emoção no desenvolvimento do "eu". Entretanto, muitas questões ainda ficam em aberto. 0 postulado da constituição social e histórica do sujeito, imerso em um mundo de signos - e formado a partir deles -, ainda suscita uma instigante discussão a respeito de como o afetivo se configura na relação com o outro, na significação que perpassa e constitui essa relação e na constituição do próprio sujeito.

Em nosso percurso de reflexão, encontramos em Elias (2001) elementos relevantes para ampliar a problematização e a discussão sobre o afetivo na relação com o outro. Ainda que se possam estabelecer distinções entre os postulados que orientam os estudos dos autores apresentados acima e os de Elias, há semelhanças expressivas no modo como compreendem a constituição do ser humano.

A sociologia configuracional de Norbert Elias preocupa-se em enfocar o ser humano em sua totalidade, sem, contudo, considerar que nossa espécie está pronta, acabada. 0 humano está em processo permanente de constituição. Esforça-se pela construção de uma abordagem que aponte a interdependência funcional entre os vários aspectos que compõem o indivíduo e os processos sociais. Nessa perspectiva, interessa-se pelo enfoque tanto de comportamentos visíveis, quanto de aspectos vivenciais, como questões referentes ao impulso e às emoções.

Um dos desafios centrais do trabalho de Elias (2001) é a preocupação em incorporar uma dinâmica temporal à concepção sociológica da pessoa, do "eu”, do indivíduo. Em relação ao nosso tema, poderíamos dizer que se trata de enfrentar o problema da dependência da criança, que gradualmente se torna um adulto - com maior poder nas relações interpessoais - e, em seguida, do idoso, crescentemente menos poderoso em relação ao adulto. A relação entre gerações é um aspecto pouco estudado, porém relevante na elaboração das Teorias dos Processos Civilizadores.

Essa dimensão histórica manifesta-se tanto através das gerações como no decorrer de nossas vidas, sendo um processo interdependente e permanente em nossa existência. As pessoas vivem e são processos. Os processos civilizadores dependem fundamentalmente do desenvolvimento humano durante sua infância. Isso quer dizer que as relações entre os adultos e as crianças estão no centro desses processos.

Em seu percurso de reflexão sobre a constituição do indivíduo, Elias (2001) também se depara com a linguagem. Ainda que de forma tímida, o autor detém-se na linguagem, destaca o sentido das palavras - e o próprio sentido da vida - e ressalta que este é atravessado pela maneira como outras pessoas o significam. Utilizando-se da noção de sentido como uma categoria social, aborda aspectos da dimensão afetiva que atravessam a vida do indivíduo na relação que este estabelece com os outros.

De suas considerações, o que nos interessa, particularmente neste trabalho, é o modo como interliga o sentido que o sujeito constrói de sua vida, de seus comportamentos, de suas produções ao sentido que os outros atribuem a ele, ao significado que ele tem para os outros. Acreditamos que uma abordagem mais aprofundada dessas considerações pode auxiliar em uma discussão sobre o componente afetivo que perpassa a significação na relação eu-outro.

Elias (2001) discorre sobre o processo de envelhecimento, a aproximação da morte e o impacto que, via de regra, esses fenômenos trazem para as relações que velhos e moribundos estabelecem com os outros e, conse- 
quentemente, para o modo como esses próprios sujeitos se veem e dão sentido à sua vida a partir dessas relações.

Afirma o autor que, atualmente, nas sociedades do mundo ocidental, o envelhecimento e a aproximação da morte têm provocado um expressivo distanciamento e isolamento de parcelas da população do convívio com os outros. Há um desconforto por parte dos vivos e dos mais jovens diante dos moribundos e dos velhos, muito provavelmente porque os últimos lembram aos primeiros o seu próprio fim - e o homem tem dificuldades de lidar com a finitude da vida individual e com o fim da própria vida. Os procedimentos médicos e hospitalares de atendimento aos doentes bem como os asilos para idosos expressam, ao mesmo tempo em que reforçam, essa maneira de ver e de lidar com esses sujeitos.

É nesse contexto que Elias (2001) discorre sobre o sentido da vida e sobre o papel que um ser humano exerce na vida de outro ser humano. Para o autor, o sentido da vida para uma pessoa tem relação com o que ela significa para os outros, o modo como concebe a si, seus sentimentos e a sua própria vida, e o valor que lhes atribui é atravessado pelo quão significativa ela é para os outros. Podemos dizer que o significado da própria vida é mediado pelo significado que os outros atribuem a essa vida. Ressalta:

É um grande apoio - encontrar eco dos seus sentimentos nos outros que se ama e a quem se está apegado, e cuja presença faz surgir um sentimento terno de pertencer à família humana. Essa afirmação mútua das pessoas através dos seus sentimentos, o eco dos sentimentos entre duas ou mais pessoas, desempenha um papel central na atribuição de significado e sentido de realização para uma vida humana - afeição recíproca, por assim dizer, até o fim. (p. 100)

Aprofundando as considerações sobre o conceito de sentido com o qual trabalha, Elias (2001) sublinha que este se distingue daquele presente em algumas reflexões filosóficas que tendem a abordá-lo, enfocando o ser humano isolado, independente dos outros.

0 que chamamos de 'sentido' é constituído por pessoas em grupos mutuamente dependentes de uma forma ou de outra, e que podem comunicar-se entre si. 0 'sentido' é uma categoria social; o sujeito que lhe corresponde é uma pluralidade de pessoas interconectadas. (p. 62-63)

Quando Elias destaca o sentido da vida, o significado que o sujeito tem para o outro ou o eco dos sentimentos entre duas ou mais pessoas, entendemos que suas palavras apontam uma discussão extremamente importante, que remete ao aspecto afetivo desse sentido e ao seu papel na vida humana.

Em sua obra, a dimensão afetiva é abordada, sobretudo, a partir da emoção.

Ressaltamos a possibilidade de síntese aberta pela proposta de Elias (1987), na medida em que estamos trabalhando nos limites entre a Biologia, a Psicologia, a Sociologia e a História. Nesse sentido, enquanto a evolução deve restringir-se aos aspectos biológicos, o desenvolvimento deve referir-se ao processo de aprendizagem e de mudanças sociais.

Para distinguir os seres humanos das outras espécies, Elias formula algumas hipóteses relativas ao processo de aprendizagem. Os seres humanos, como uma espécie, representam uma ruptura evolucionária, pois o equilíbrio de poder entre condutas aprendidas e não aprendidas tomou um novo rumo. Pela primeira vez no processo evolucionário, modos predominantemente aprendidos de direcionamento comportamental tornaram-se, de forma clara e incontestável, dominantes em relação aos modos predominantemente não aprendidos.

A segunda hipótese destaca que os seres humanos não somente podem aprender muito mais que as outras espécies. Eles também devem aprender mais para se tornar seres humanos que funcionam plenamente. Nos huma- 
nos, formas não aprendidas de direcionamento de condutas perderam sua rigidez genética e tornaram-se amalgamadas e subordinadas a formas aprendidas como a comunicação, a orientação ou o conhecimento social preexistente.

Por último, é preciso considerar que nenhuma emoção de uma pessoa adulta é, em qualquer caso, um padrão reativo geneticamente fixado. As emoções resultam de uma mescla de processos aprendidos e não aprendidos, portanto, atuam componentes culturais e biológicos, e a aprendizagem é um elemento fundamental nos níveis do comportamento e da sensibilidade.

Por outro lado, além do termo emoção, é importante, para a nossa reflexão, enfocar também alguns sentidos que atravessam o vocábulo afeto. Afetivo, afeto e afetividade são termos marcados por certa dificuldade de conceitualização. Na literatura psicológica de origem latina, afirma Pino (1998), o termo afetividade é abordado de forma genérica e caracterizado por uma concepção idealista da vida afetiva, diferentemente do vocábulo emoção, de modo geral abordado de forma restrita e marcado por uma concepção mais mecanicista. Discorrendo sobre a dualidade que atravessa a discussão dos termos afetividade e emoção, o autor afirma:

Enquanto o primeiro nos refere muito mais ao conteúdo vivência do que ao componente biológico dos comportamentos humanos, enfatizando o que há de diferente entre o homem e o animal, o segundo nos refere muito mais ao componente biológico do que ao conteúdo vivência, enfatizando o que há de mais semelhante entre ele e o animal. Essa dualidade conceitual tem a ver, certamente, com o dualismo que perpassa a história da psicologia e que se traduz na oposição entre racionalidade e impulsividade: vista aquela como expressão da humanidade e esta como resíduo da herança ancestral animal. (p. 129-130)

Como ir além da dualidade e pensar uma noção de afetivo que busque compreender o sujeito em uma perspectiva de totalidade? Como articular o biológico e o vivencial, o afetivo e o emocional? Pode a abordagem da significação contribuir para isso? De que maneira?

Para Pino (1998), os fenômenos afetivos referem-se a "[...] experiências subjetivas que traduzem a maneira como cada sujeito é afetado pelos acontecimentos da vida ou, melhor, pelo sentido que tais acontecimentos têm para ele" (p. 128, grifos do autor). Tais considerações remetem-nos novamente à questão da relação entre o afetivo e a significação e aguçam nosso interesse em compreender um pouco mais sobre essa relação.

As ideias de Pino e de Elias sobre o aspecto afetivo da relação com os outros e a maneira como o sujeito é afetado pelos sentidos que os outros atribuem a ele levam-nos a indagações a respeito de como, no processo interativo, as crianças vão elaborando/significando/vivendo afetivamente essa relação com o outro e significando a si próprias nessa relação. Suscitam-nos também questionamentos a respeito da participação dos adultos nesse processo.

Para auxiliar na reflexão sobre essas questões, buscamos elementos no material coletado em uma pesquisa realizada com crianças em uma brinquedoteca, que teve como objetivo investigar aspectos referentes ao afeto, à emoção e à linguagem na brincadeira da criança. Os sujeitos eram 15 crianças oriundas de um orfanato, com aproximadamente quatro a seis anos de idade, e duas crianças com síndrome de Down, que viviam com suas famílias. Um trabalho prático foi realizado com essas crianças no espaço da brinquedoteca, no transcorrer de quatro meses, e contou, também, com a participação de três estagiárias de pesquisa. Nos encontros com as crianças, eram realizadas algumas atividades dirigidas e outras não dirigidas.

Para o presente trabalho, optamos por enfocar uma criança com síndrome de Down, tendo como eixo para a discussão os modos de viver e de significar a relação com os outros e consigo mesma. 


\section{Dinâmica interativa e construção de sentidos sobre o eu e o outro no espaço da brinquedoteca}

Marcelo ${ }^{1}$ tinha cinco anos quando a pesquisa iniciou. Era o mais novo dos dois filhos de uma família e seu irmão mais velho tinha aproximadamente nove anos. Marcelo frequentava a APAE no periodo matutino.

Tinha dificuldades em articular os sons das palavras, o que interferia na compreensão, por adultos e outras crianças, do que ele queria dizer. Apesar disso, falava bastante. Geralmente apresentava expressões faciais mais marcantes e gesticulava muito em momentos de interação tanto com os outros como consigo mesmo diante do espelho. Um aspecto que o distinguia de outras crianças era o fato de utilizar, com muita frequência, manifestações afetivo-emocionais mais explícitas na relação com os outros, tanto adultos como crianças, meninos ou meninas. Marcelo constantemente tentava tocar, acariciar, abraçar e beijar os outros, mas em certos momentos, essa atitude causava estranheza nas crianças, acarretando uma recusa das manifestações e um afastamento de Marcelo.

Nos primeiros encontros realizados na brinquedoteca, Marcelo esteve a maior parte do tempo no "Cantinho da Casinha" e ficou entretido com bonecas: manuseava-as, mexia em suas roupas, penteava seus cabelos e, às vezes, falava enquanto estava envolvido com elas. No início, interagiu pouco com outras crianças. Costumava ir para a frente do espelho e interagia com a própria imagem. Durante todo o trabalho prático realizado na brinquedoteca, Marcelo manteve mais contatos com as pesquisadoras, as quais o abordavam frequentemente, conversavam com ele, apesar de nem sempre conseguirem compreender o que dizia. Brincavam com ele, tentavam inseri-lo no jogo imaginário, procuravam estimular e mediar a relação entre ele e outras crianças.

Nesse contexto, indagamo-nos a respeito dos sentidos que se vão construindo, para
Marcelo, nas relações com os outros: a maneira como, em seus cinco anos de idade, elabora o "sentido" que tem para os outros e o impacto disso para o modo como significa a si próprio e a sua vida.

Destacamos, a seguir, um evento que, a nosso ver, é relevante para ilustrar a maneira como os adultos (pesquisadoras) procuravam relacionar-se com Marcelo na brinquedoteca.

A pesquisadora ajuda Marcelo a colocar uma fantasia de Fantasma ${ }^{2}$ e, em seguida, mostralhe como um fantasma faz: levanta os braços e diz: “Ahh!". Com a fantasia, Marcelo vai para a frente do espelho, inclina-se e começa a conversar com a sua imagem, depois sai correndo pela brinquedoteca. Uma criança fantasiada de Batman passa a capa sobre a cabeça de Marcelo e o agarra, envolvendo seu corpo com os braços. A fantasia de Marcelo cai e a pesquisadora colocaa novamente. Mais uma vez ele vai para a frente do espelho e olha-se, depois, vira-se, coloca as mãos na cabeça e caminha na direção da pesquisadora. Ao vê-lo, ela finge assustar-se, coloca as mãos no rosto e fala para Deise, outra criança: "0 fantasma!". Marcelo abraça a pesquisadora que estava sentada no chão e eles caem. Simulando precisar de ajuda, a pesquisadora fala: "Por favor, alguém me ajuda!”. Marcelo levanta-se e tira a fantasia. A pesquisadora olha e diz: “O fantasma que virou Marcelo!". Ela coloca a fantasia de fantasma e diz: "Agora eu sou o fantasma!". Outra pesquisadora sugere: “Corre, Marcelo!”. Fantasiada, a pesquisadora movimenta-se tentando iniciar um jogo de assustar. Marcelo apenas observa, não assume o papel de quem se assusta. A pesquisadora fala: “Eu vou te pegar!”. Ele continua a olhar para ela sem se movimentar.

1. Os nomes dos sujeitos envolvidos na pesquisa em tela e apresentados neste trabalho são fictícios.

2. A fantasia consistia em um corte de tecido branco, com abertura para os olhos, que a criança colocava sobre a cabeça. Para o tecido não cair, na parte do avesso da fantasia, estava afixado um pequeno arco, que a criança colocava sobre a cabeça. 
Então, a segunda pesquisadora diz: "Corre, corre!”, mas ele continua olhando para ela, com a cabeça inclinada. A pesquisadora fantasiada abraça-o e ele sorri.

Nesse evento, assim como em muitos outros registrados durante o trabalho prático, pesquisadoras e Marcelo interagiram e envolveram-se em uma situação de jogo imaginário. Como normalmente ocorria, as pesquisadoras criavam situações para levar Marcelo a participar e/ou criar brincadeiras de faz-de-conta.

Objetivando possibilitar condições para que Marcelo compreendesse como funciona a brincadeira de "assustar o outro", na situação descrita, duas pesquisadoras orientaram-no sobre como atuar. A primeira ajudou Marcelo a vestir a fantasia e assumiu o papel de quem se assusta ao vê-lo fantasiado de fantasma. Depois, colocou a fantasia de fantasma e, assumindo o papel de quem assusta, movimentou-se sob o tecido branco. A segunda pesquisadora disse a Marcelo o que ele devia fazer para participar da brincadeira: sugeriu que ele corresse. Entretanto, nesse momento, ele ainda não tinha condições de entender a dinâmica desse jogo de faz-de-conta. Não conseguia assumir nem o papel de quem assusta - em vez de continuar "assustando" a pesquisadora, que simulou susto ao vê-lo, ele a abraçou - nem o papel de quem se assusta enquanto a pesquisadora desenvolvia ações para assustá-lo, Marcelo olhava para ela, parecendo não compreender o que estava acontecendo.

Entretanto, o fato de o jogo imaginário não se concretizar, pois Marcelo não assumiu o seu papel nem desenvolveu os gestos e as ações pertinentes a ele, não dificultou a interação entre eles e certamente contribuiu para a apropriação de um tipo de brincadeira muito comum entre adultos e crianças e entre as próprias crianças. 0 que nos parece relevante destacar é o modo como pesquisadoras e criança se colocam no jogo interativo: se a relação não é simétrica, já que se trata de adultos e criança, cada um ocupa um lugar na relação que lhe confere respeito e consideração por parte do outro. Esse outro é alguém com quem se pode brincar, abraçar e trocar sorrisos. Parece ser possivel dizer que, nessa situação, o lugar ocupado pelos atores na relação situa cada um deles como um ser significativo para o outro, ainda que se possam estabelecer diferenças sobre o modo como essa situação repercute em cada participante individualmente.

É importante ressaltar que, durante todo o trabalho prático realizado com as crianças, fazia parte dos objetivos criar condições para a inserção adequada de Marcelo nas atividades desenvolvidas na brinquedoteca, fossem elas dirigidas ou não, bem como para a mediação da relação entre ele e as outras crianças.

No entanto, apesar do esforço das pesquisadoras nesse trabalho mediador, as interações estabelecidas entre Marcelo e as outras crianças envolviam modos diferenciados de relação. 0 evento descrito abaixo destaca uma situação de conflito, bastante comum a partir de certo tempo, quando ele tentava aproximar-se dos colegas.

No evento, Deise (6 anos) e Kátia ( 5 anos) estavam brincando com uma barraquinha ${ }^{3}$. Elas saíam da barraquinha e Marcelo entrava, mas Deise não queria que ele se envolvesse com a brincadeira delas.

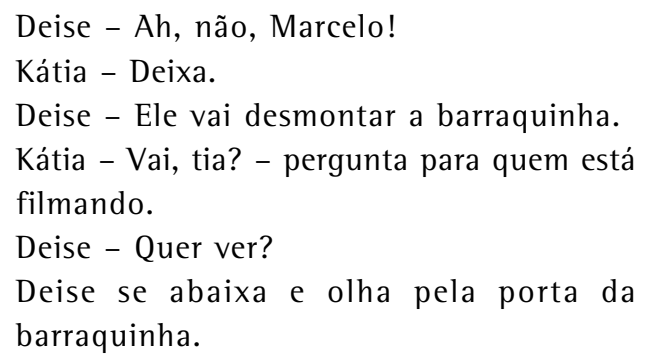

A casinha vira e fica de lado. Marcelo cai. Como a barraquinha não é coberta por tecido na parte que corresponderia ao piso, é possível ver Marcelo deitado sobre uma das paredes de pano. A pesquisadora tenta levantar a barraquinha, mas ele se senta sobre o tecido da parede, impedin-

3. É uma barraquinha da turma da Mônica. É feita de pano, com uma armação de plástico. Tem uma abertura central, a porta, e outra menor em uma das laterais, a janela. 
do-a de colocar novamente a barraquinha na posição apropriada.

Pesquis. - Vai deixar assim, para entrar um ar na casinha?

Deise - Eu não vou mais morar nessa casinha, esta casinha tá muito chata.

Kátia - Eu vou - e entra na casinha com Marcelo.

Pesquis. - Quem mora nesta casinha? Kátia

e Marcelo é que moram nessa casa?

Deise: Eu também moro na casinha com a nenê e a Adriana.

Criança - Eu também moro na casinha.

Essa cena descreve uma situação de interação envolvendo Marcelo, duas meninas Deise e Kátia - e uma das pesquisadoras que, nesse dia, estava filmando fragmentos de eventos ocorridos durante o encontro. É possível perceber, na narrativa apresentada, que os sujeitos envolvidos se posicionavam de forma diferenciada na relação que estabeleciam com Marcelo e/ou na maneira de se colocar diante dele.

Nessa ação de Marcelo entrar na barraquinha (talvez uma tentativa de se inserir na brincadeira das duas), Deise manifestou o seu descontentamento com a justificativa de que ele ia desmontar a barraquinha. Alguns segundos depois, ela não se desmontou, mas virou de lado.

Posicionamentos semelhantes ao de Deise foram percebidos em outros momentos do trabalho realizado com as crianças. À medida que Marcelo foi se sentindo mais à vontade na brinquedoteca, foi circulando mais pelas duas salas que a compunham, explorando diferentes espaços e tentando inserir-se nas brincadeiras de outras crianças ou simplesmente interagir com elas. Entretanto, na maior parte das vezes, essa inserção não era muito fácil, pois Marcelo não conseguia ter ações apropriadas à atividade em curso e as crianças nem sempre tinham disposição em auxiliá-lo: ele tirava objetos utilizados por elas nas brincadeiras sem pedir, escondia peças dos jogos quando outras crianças estavam brincando. Devido às peculiaridades de seu movimen- to, derrubava objetos e brinquedos que estavam sendo utilizados pelos outros. Algumas vezes, ainda que ele não participasse adequadamente das brincadeiras, as outras crianças não se incomodavam com a sua presença, mas, na maioria das vezes, seu envolvimento gerava conflitos.

Diante disso, aos poucos, entre algumas crianças, foi-se criando uma imagem de Marcelo como a de alguém que atrapalhava a brincadeira dos outros. Isso foi manifestado nos comentários de Deise. Algumas crianças começaram a rejeitar a presença dele nas brincadeiras.

Nessas situações, Marcelo falava pouco e nem sempre era possível compreender o que ele falava. Seus gestos pareciam dizer mais que as palavras. Às vezes, tentava afagar, acariciar aquele que o estava rejeitando. Em outros momentos, mexia em algum objeto que fazia parte da brincadeira, atrapalhando.

As pesquisadoras ficavam atentas às interações entre Marcelo e as outras crianças e, na medida do possível, procuravam mediar tanto a sua inserção nas brincadeiras como os conflitos que se estabeleciam entre eles. Entretanto, nem sempre isso era possível.

Um evento observado após uma dessas situações tensas com outras crianças trouxe indícios relevantes para aprofundar a discussão sobre o modo como repercutiam nele essas relações com os outros:

Marcelo e outras crianças estão no "Canto da Casinha”. Ele pega a boneca que estava com Deise. Ela vai atrás dele e faz movimentos com uma das mãos de quem vai bater nele. Ele para e ela puxa a boneca de sua mão. Ele pega um outro brinquedo que estava no sofazinho, Érika puxa-o de sua mão. Ele pega outra boneca e vai em direção à pesquisadora, que está com uma máquina fotográfica de brinquedo na mão. Ele se aproxima da máquina e a pesquisadora pergunta: "Quem está aí do outro lado?". Ele coloca a boneca no chão, pega a máquina e começa a tirar fotos da pesquisadora. Uma criança tenta tirar a máquina da mão de 
Marcelo, mas ele não deixa e continua a tirar fotos da pesquisadora, sorrindo bastante. Em seguida, a pesquisadora pega a boneca que estava com ele, mostra-a e ele bate na boneca. A pesquisadora abraça a boneca e indaga: "0 que aconteceu?". Marcelo se aproxima da pesquisadora e bate novamente na boneca, com uma expressão séria, mordendo os lábios. A pesquisadora afaga a boneca e pergunta: "O que ela fez?". Ele bate na boneca mais uma vez e depois começa a mexer no cabelo da pesquisadora.

Nas mãos de Marcelo, as bonecas eram frequentemente cuidadas e acariciadas. Entretanto, nesse evento, após uma situação de conflito vivida com duas meninas, a boneca transformou-se em objeto para ele bater. Deise tirou a boneca das mãos de Marcelo e fez gestos de quem ia bater nele. Érika tirou de suas mãos outra boneca, que ele pegou ainda no espaço da "Casinha". Outra criança tentou tirar a máquina fotográfica de suas mãos, embora sem êxito. Ao final do evento, Marcelo bateu na boneca repetidas vezes.

Analisando a situação, é possível levantar a hipótese de que, nesse caso, a boneca era mais que um simples brinquedo que ele manipulava, representava algo mais. Ainda que provavelmente não de forma clara para ele nem deliberada, o imaginário entrou em funcionamento e a boneca adquiriu um novo sentido: um sentido marcado, possivelmente, pelas sensações desagradáveis que causaram nele as situações de conflito vivenciadas com os colegas minutos antes.

Estudos desenvolvidos por Vigotski (1987) a respeito da relação entre atividade criadora, imaginação e emoção apontam a viabilidade dessa hipótese. 0 autor destaca, por um lado, o suporte essencial que a realidade fornece para a atividade imaginária, na medida em que oferece o substrato básico sobre o qual a imaginação se apoiará em suas combinações e recombinações. Nesse sentido, ele afirma:

En ello [realidade] encontramos la primera y principal ley a que se subordina la función imaginativa. Podría formularse así: la actividad creadora de la imaginación se encuentra en relación directa con la riqueza y la variedad de la experiencia acumulada por el hombre, porque esta experiencia es el material con el que erije sus edificios la fantasia. Cuanto más rica sea la experiencia humana, tanto mayor será el material del que dispone esa imaginación. Por eso, la imaginación del niño es más pobre que la del adulto, por ser menor su experiencia. (p. 17)

Por outro lado, aponta a participação do emocional que, sob diferentes estados de ânimo, interfere nos rumos da atividade imaginária. A emoção configura-se, para ele, como um elemento que concede certa tonalidade e direcionamento a pensamentos, imagens e impressões do sujeito. Segundo o autor,

[...] todo sentimiento, toda emoción tiende a manifestarse en determinadas imágenes concordantes con ella, como si la emoción pudiese elegir impressiones, ideas, imagenes congruentes con el estado de ánimo que nos dominase en aquel instante. (p. 21) ${ }^{4}$

Por outro lado, os enunciados de Kátia "Deixa!", "Vai, tia?" - apontavam uma maneira um pouco diferenciada de se colocar diante de Marcelo. Kátia parecia não se incomodar com a sua entrada na barraquinha e também demonstrou não compartilhar os mesmos sentidos que atravessavam as palavras de Deise sobre ele. Quando a barraquinha caiu, ela entrou e ficou com o menino durante algum tempo.

Durante os encontros, presenciamos situações, embora em menor número, em que Marcelo se inseriu e/ou foi inserido por outras crianças em algumas brincadeiras, sem que houvesse rejeição ou conflito na relação com os colegas. De modo geral, nessas brincadeiras, sua participação era limitada, ele pouco atua-

4. Ao se referir ao estado de ânimo que orienta a determinação das imagens, Vigotski indica manifestações como alegria, tristeza, medo, dor, calma, entre outras. 
va, apenas sofria a ação desenvolvida por outros. Podemos citar exemplos de uma brincadeira em que ele foi fotografado por uma outra criança com uma máquina de brinquedo; uma situação em que duas meninas se aproximavam dele com pompons e os sacudiam na cabeça dele; e um evento em que uma menina, que estava com um fantoche, aproximava-o de seu rosto, tocando-o algumas vezes, simulando dar beijinhos nele.

Brincadeiras que implicavam uma participação mais intensa e sofisticada por parte de Marcelo costumavam ocorrer mais quando uma das pesquisadoras participava, auxiliando-o na execução das ações apropriadas.

Por outro lado, havia uma menina, em especial, para a qual as dificuldades de Marcelo se fazer entender pela fala e as ações pouco apropriadas pareciam não ser empecilho para a relação e a brincadeira conjunta. Isadora era a criança que interagia com Marcelo de forma mais frequente na brinquedoteca.

\section{A relação (significativa) entre Marcelo e Isadora}

lsadora (5 anos) vivia no orfanato desde os três meses de idade. Deixada na porta do orfanato pela mãe altas horas da noite, faminta, desnutrida e com uma ficha do berçário em que ficara ao nascer, ela foi encontrada e acolhida pelo administrador, que a registrou no cartório. Após algum tempo, a mãe foi identificada e consultada sobre a possibilidade de voltar a cuidar da filha, e a resposta foi negativa. A mãe não trabalhava na época, vivia pelas ruas, praticava pequenos furtos e já fora presa várias vezes. Também era oriunda de uma família com membros envolvidos com drogas, dois dos quais haviam sido assassinados. Isadora foi vítima de maus tratos por parte da mãe e, talvez, em consequência disso, demorou aproximadamente um ano e meio para interagir com mulheres que trabalhavam no orfanato sem demonstrar irritação ou chorar. Caso uma mulher se aproximasse dela ou gritasse perto dela, lsadora es- perneava e chorava compulsivamente. Interagia melhor com o Coordenador do orfanato que informou tê-la adotado como filha. Na brinquedoteca, ela não parecia ter dificuldades de se relacionar com as outras crianças e com os adultos, circulava por todos os cantos temáticos, brincava sozinha e com outras crianças, adorava vestir uma fantasia de noiva. Entretanto, um aspecto que a diferenciava das outras crianças era o fato de chorar por muito tempo em momentos em que era contrariada.

lsadora e Marcelo relacionavam-se e brincavam com relativa frequência. A situação descrita abaixo ilustra um dos momentos em que isso aconteceu.

Marcelo e lsadora envolvem-se em uma brincadeira que ora se assemelha às brincadeiras de assustar, frequentes entre as outras crianças nesse período, ora se parece com pega-pega. Diante de lsadora, Marcelo grita: “Ahh!”. Ela corre e Marcelo vai atrás dela. Enquanto correm, os dois dão gargalhadas. Eles param no meio da brinquedoteca. Ele estende o braço direito e abre e fecha a mão algumas vezes, num gesto que parece significar um chamado. Depois, ele caminha na direção de lsadora com os braços estendidos e ela corre. Isadora para novamente no meio da brinquedoteca, chega perto de Marcelo, toca-o e pronuncia seu nome de forma melodiosa: "Marcelo, Marcelo..." - como se estivesse provocando-o ou desafiando-o a pegá-la. Em seguida, corre novamente, e ele corre atrás dela.

No evento descrito, é possível perceber uma grande sintonia entre Marcelo e Isadora nas diferentes etapas da brincadeira. Em um primeiro momento, ele assumiu o papel daquele que assusta e apresentou ações apropriadas ao papel que assumiu: aproximava-se de lsadora e gritava “Ahh!". Diante de sua fuga, ele a perseguia, corria atrás dela como faziam outras crianças no mesmo tipo de brincadeira. Em seguida, diante das provocações e/ou desafio de Isadora, corria novamente atrás dela. Ela o 
constituía como um parceiro para a brincadeira e ele se envolvia adequadamente no jogo e demonstrava muita satisfação com isso: ria, dava gargalhadas.

Tendo em vista o modo como era tratado por algumas outras crianças, a relação com lsadora e a brincadeira em que se envolvia com ela, sem a mediação de um adulto, era extremamente significativa.

Ao contrário da interação estabelecida com a maioria das outras crianças, na relação com Isadora, Marcelo ocupava uma posição diferenciada. Nesse relacionamento, ele se constituía como um legítimo parceiro para a brincadeira, alguém com quem se poderia divertir, rir e dar gargalhadas. Na verdade, o reconhecimento do outro como um parceiro para as brincadeiras, nesse caso, não é unilateral, é mútuo: tanto lsadora como Marcelo atribuíam um ao outro o status de parceiro na brincadeira.

Retomando as palavras de Elias (2001) a respeito do significado e do sentido que tem para a realização da vida a afirmação mútua das pessoas pelos dos sentimentos compartilhados com o outro, podemos indagar-nos sobre o quanto, nesse momento, Marcelo e Isadora compartilham sentimentos de um em relação ao outro. Que há uma constituição mútua, é inegável, nesse caso, que tanto ele quanto ela participam na constituição um do outro. Para nossa reflexão, interessa discutir sobre o afeto que perpassa e constitui essa relação, sobre os possíveis ecos dos sentimentos de um em relação ao outro, tal qual ressalta Elias.

Na brincadeira, há uma reciprocidade nos papéis assumidos pelas crianças: uma grita e "assusta", a outra "se assusta" e corre; uma corre e a outra corre atrás. Há uma relativa alternância nos papéis, na medida em que ora uma provoca a situação que dá início à perseguição, ora outra determina o motivo do correr atrás. Há também uma complementaridade: uma ação complementa a outra, produzindo certa unidade à brincadeira - as duas crianças compõem um único todo que configura a própria brincadeira.
É nesse contexto lúdico, caracterizado pela reciprocidade e alternância de papéis, pela complementaridade das ações e por um efeito de unidade (os dois compõem um) na brincadeira, que o prazer emerge e o riso e as gargalhadas se fazem presentes. Ambas as crianças participam da construção da brincadeira e do delineamento das sensações agradáveis e da euforia que ela produz em cada um deles. Compartilham da configuração do contexto em que a emoção emerge e também da própria emoção.

Concordando com Wallon (1975), talvez seja possível dizer ainda que, momentaneamente, as emoções que emergem no jogo imaginário provocam uma dissolução das fronteiras entre o eu e o outro, contribuindo assim para esse efeito de unidade: “A emoção leva às impulsões coletivas, à fusão das consciências individuais numa única alma comum e confusa" (p. 154).

Nessa situação, consideramos que o modo como a brincadeira se desenrola apresenta indícios que permitem tecer comentários a respeito de certa partilha de sentimentos de uma criança com relação à outra, dos ecos dos sentimentos de uma em relação à outra, tal qual fala Elias. Na relação, ambas as crianças parecem apresentar-se como significativas uma para a outra. 0 que nos leva a levantar essa hipótese com mais tranquilidade é o fato de Marcelo ser parceiro de lsadora também em outras atividades lúdicas. Observamos outras situações em que os dois interagiam e brincavam em espaços diferentes da brinquedoteca, de forma semelhante à descrita.

No entanto, embora encontremos indícios de que um se constituía em alguém significativo para o outro, naquele período, isso não quer dizer que a relação entre ambos também não fosse permeada por conflitos, como pode ser percebido no evento descrito a seguir.

Isadora e Marcelo brincam com um jogo de encaixe. Ela começa a guardar as peças e ele segura algumas delas. Ela tenta tirálas de suas mãos e bate com uma das peças em seu braço. Ele esconde uma peça atrás 
do seu corpo e, quando ela vai pegá-la, ele a joga longe. lsadora continua a guardar os encaixes com um semblante muito sério. Marcelo a observa segurando em suas mãos duas peças. Ela as toma dele e as guarda. Ele a abraça e tenta beijá-la. Ela tira uma peça que estava debaixo de sua perna e ele a empurra com as mãos. Ela fala: "Para!" - e dá um tapa em sua mão. Depois, levanta-se e empurra-o. Ele vira o corpo na direção dela e começa a falar, balançando os braços. Isadora vai para outro canto e ele continua a olhar para ela. Marcelo aproxima-se, toca no braço de lsadora, que diz algo inaudível. Ela olha para ele e se afasta.

Se Marcelo era parceiro para atividades prazerosas, também o era para as situações de conflito. Na cena descrita, após brincar, lsadora quis guardar as peças do jogo, mas Marcelo não deixou, não aceitou ou não compreendeu que ela queria parar a atividade lúdica, pois ele escondeu as peças que ela queria guardar e ela as tirou dele. Diante da atitude mais ríspida de Isadora, Marcelo teve uma reação que se repetiu com relação a outras crianças em outros momentos. Ele a abraçou e tentou beijá-la. Ela recusou esse tipo de manifestação, pronunciando-se verbalmente, bateu em sua mão e, não satisfeita com isso, levantou-se e empurrou-o.

Reações de desagrado diante da atitude de Marcelo foram percebidas em outros momentos por parte de lsadora quando os dois brincavam juntos. A repreensão verbal ou mesmo o bater foram observados em uma situação em que ela queria que ele brincasse com determinadas peças de um jogo e ele queria outras e, também, em um evento em que ele queria deitar-se nos tapetinhos que lsadora separou para se acomodar sozinha enquanto ouvia histórias.

Parece ser possível dizer que lsadora o via e se relacionava com ele como um "igual". Brincava, divertia-se, mas não fazia concessões. Também ficava brava e batia nele se fosse contrariada, semelhante ao que faziam outras crianças em alguns momentos. No entanto, ainda assim se pode dizer que Marcelo ocupava um lugar diferenciado na relação estabelecida: ela se relacionava com ele da mesma forma como se relacionava com outras crianças, pois havia uma equivalência no modo de tratamento.

Para ela, Marcelo não parecia ser somente o menino que atrapalhava as brincadeiras ou que "tinha problemas", conforme apontou uma das crianças mais velhas do orfanato. Significava mais que isso.

Tal fato leva-nos a indagações que remetem ao que significa ser significativo para o outro. Quando e em que condições alguém se torna importante ou especial para o outro? É possível falar em um sentido único envolvendo o modo como cada um percebe o outro e lhe atribui valor? É possível destacar um sentido único para a maneira como se é afetado pelo outro, para o afeto dirigido ao outro?

Os sentidos que atravessam a relação estabelecida entre Marcelo e lsadora, na brinquedoteca, remetem-nos às considerações de Bakhtin (1986) a respeito do caráter polissêmico e ideológico dos signos. Para o autor, os signos apresentam-se como "[...] uma arena em miniatura onde se entrecruzam e lutam valores sociais de orientação contraditória" (p. 66). Ou seja, os sentidos que atravessam a dinâmica interativa - configurados nas palavras, nos olhares, nos sorrisos, nos gestos - constituem-se no desenrolar desse processo, configuram-se a partir das posições ocupadas pelos interlocutores e em dependência do contexto imediato e mais amplo em que a interação ocorre. E é nesse contexto que consideramos relevante pensar o aspecto afetivo e a significação.

0 que se evidencia na análise é a presença de uma multiplicidade de sentidos envolvendo o modo como os sujeitos são "significados" na relação. Uma série de fatores atravessa e compõe essa significação, que não é unívoca. Os sentidos atribuídos ao outro não são estáticos. Ao contrário, caracterizam-se por uma maleabilidade e uma plasticidade em que se ressaltam até formas de sentir contraditórias: pode-se buscar uma aproximação do outro, 
compartilhar com ele momentos extremamente prazerosos e, em outros momentos, ser afetado por sua presença, por suas ações, ou pelas lembranças que este provoca a tal ponto de se buscar repeli-lo pelas sensações desagradáveis que desencadeia.

0 que se sente em relação ao outro e o modo de significar esse sentir são atravessados pelos diferentes contextos em que os sujeitos interagem, pelos elementos em jogo na relação, pelas posições ocupadas pelos envolvidos, pela história de vida de cada um.

Nas duas últimas situações em foco, temos dois sujeitos: Marcelo e lsadora. Buscamos compreender como ela se apresenta como o outro da relação com ele e como os sentidos que se constroem nessa relação o afetam e interferem no seu modo de ser e de agir na brinquedoteca.

Entretanto, a análise revela-nos a complexidade que envolve o modo como um sujeito é afetado pelo outro e como significa esse outro na dinâmica interativa. Nas relações estabelecidas, não é possível destacar um sentido único perpassando a forma como lsadora concebe Marcelo e a maneira como se relaciona com ele. E provavelmente também não será possível apontar um sentido único para o modo como ele, em seus cinco anos, elabora o sentido que tem para ela.

\section{Considerações finais}

0 interesse em aprofundar a discussão a respeito da dimensão afetiva que atravessa a relação eu-outro e a constituição do sujeito levou-nos a focalizar as crianças pequenas e a tematizar o modo como vivenciam afetivamente as relações no espaço de uma brinquedoteca e a maneira como significam a si e ao outro nessa relação.

A retomada das formas de relação estabelecidas entre uma criança com síndrome de Down e as outras crianças e adultos e a análise esboçada de alguns eventos ocorridos durante os encontros na brinquedoteca permitiram-nos destacar alguns aspectos para a dis- cussão sobre o afetivo e a significação nas interações estabelecidas.

Elias (2001) afirma que há uma relação entre o sentido da vida e o significado que uma pessoa tem para a outra, isto é, a maneira como um ser humano concebe a si próprio tem relação com o que ele significa para os outros. A análise de aspectos da relação estabelecida entre Marcelo e lsadora evidencia que discutir o sentido que um sujeito tem para o outro implica abordar, também, o contexto em que ambos interagem e a maneira como a relação se configura em momentos diferenciados. Em situações distintas, o modo como uma criança se relaciona com a outra pode ser diferente e as repercussões afetivas que atravessam essa relação também podem ser diferentes. Na relação estabelecida com o outro, mais do que um sentido único, o que se destaca é uma multiplicidade de sentidos a respeito desse outro, acompanhada de ressonâncias afetivas que podem ser variadas e até contraditórias.

Entretanto, ainda que a multiplicidade de sentidos e as repercussões afetivas diferenciadas se configurem, isso não quer dizer, necessariamente, que um sujeito deixa de ser significativo para o outro. Não é o fato de a relação ser perpassada apenas por sensações agradáveis e prazerosas que define se alguém é ou não significativo para o outro. Mais relevante para essa definição parece ser o lugar em que ambos os sujeitos colocam um e outro e a repercussão que isso tem para a relação.

No jogo imaginário entre Marcelo e lsadora, destacam-se alguns aspectos importantes para essa reflexão: a reciprocidade e a alternância de papéis que cada um deles assume na brincadeira, a "complementaridade" das ações e o efeito de "unidade" que as acompanha. Contribuindo para esse efeito, destacamse as emoções que emergem durante o jogo imaginário: risos e gargalhadas fornecem indícios para identificação do prazer e da euforia que acompanha o jogo entre as duas crianças. Emoções que podem contribuir, ainda que momentaneamente, para diluir as fronteiras que separam o "eu" e o outro. 
Nessa diluição das fronteiras, na relativa (con)fusão das consciências, (con)fundem-se também as próprias sensações, os afetos.

Entretanto uma questão se coloca a respeito da significação. Se, como afirma Wallon (1975), “[...] a emoção corresponde a estado psíquico mais primitivo que a tomada de cons- ciência pela qual a pessoa afirma a sua autonomia, [se ela] [...] depende duma vida psíquica ainda mal diferenciada [...]" (p. 154), tal fato traz indagações a respeito de como os sentidos se produzem nesse universo. É possível dizer que há algo de peculiar em sua produção nesse espaço? Questões que demandam novos estudos.

\section{Referências bibliográficas}

BAKHTIN, M. Marxismo e filosofia da linguagem. 3. ed. São Paulo: Hucitec, 1986.

ELIAS, N. A solidão dos moribundos: seguido de envelhecer e morrer. Rio de Janeiro: Jorge Zahar, 2001.

. On human beings and their emotions: a process sociological essay. Theory, culture and society, London/New York, v. 4 , n. 2-3, p. 339-361, jun. 1987.

PINO, A. Afetividade e vida de relação. 1998. Texto do curso "Seminários Avançados em Psicologia da Educação" oferecido pelo Programa de Pós-Graduação em Educação da UNICAMP, Campinas, 1998.

VIGOTSKI, L. S. La imaginacion y el arte en la infancia (ensayo psicológico). México: Hispanicas, 1987.

Teoria e método em psicologia. São Paulo: Martins Fontes, 1996.

Manuscrito de 1929. Educação e Sociedade, Campinas, n. 71, p. 21-44, 2000.

WALLON, H. Psicologia e educação da infância. Lisboa: Estampa, 1975.

Recebido em 08.06.09

Aprovado em 06.10 .09

Ivone Martins de Oliveira, pedagoga, mestre e doutora em Educação pela UNICAMP, é professora da Universidade Federal do Espírito Santo e tem como linha de pesquisa: Diversidade e Práticas Educacionais Inclusivas.

Ademir Gebara, graduado em História e Educação Física (PUCC), mestre em História Social (USP), Ph. D. em História Econômica pela London School of Economics and Political Science da Universidade de Londres, é Coordenador do Grupo de Pesquisa Processos Civilizadores. E-mail: am_gebara@yahoo.com.br. 